\title{
A prospective evaluation of cytology from biliary strictures
}

\author{
J C Mansfield, S M Griffin, V Wadehra, K Matthewson
}

\begin{abstract}
Background-Bile duct strictures may be benign or malignant. A definite diagnosis is desirable to advise patients of their prognosis and to identify any amenable to curative surgery.
\end{abstract}

Aims-To compare different methods of cytology sampling from biliary strictures and evaluate the use of cytology in this context.

Patients and methods-In a prospective study 54 patients undergoing endoscopic retrograde cholangiopancreatography (ERCP) had cytology samples obtained as follows: (1) biliary stricture brushings, (2) from the screw thread of a "Soehendra stent retriever" inserted through the stricture, (3) from the proximal end of a blocked biliary stent, and (4) cellular material spun down from a $20 \mathrm{ml}$ specimen of bile. Examination of slides and rinsings was performed by an expert cytologist who graded them for the adequacy of the sample and for evidence of malignancy.

Results-Prolonged follow up disclosed malignancy in 52 of the 54 cases, the other two being chronic pancreatitis. Bile samples provided adequate cytology samples in $44 \%$, the Soehendra stent retriever in $70 \%$, retrieved stents in $84 \%$, and cytology brush sampling in $96 \%$. Overall, 28 malignancies were detected by cytology, including 14 of 28 pancreatic carcinomas and 12 of 16 cholangiocarcinomas. Twenty two of the malignancies were detected by brush sampling and the other methods added a total of another six cases.

Conclusions-Cytology sampling is best done by brushing the biliary stricture. Cytology sampling can confirm the diagnosis in $75 \%$ of cholangiocarcinomas and $50 \%$ of pancreatic carcinomas. The techniques involved are simple to perform and should be routine clinical practice whenever potentially malignant biliary strictures are encountered at ERCP.

(Gut 1997; 40: 671-677)

Keywords: biliary strictures, cytology, pancreatic carcinoma, cholangiocarcinoma.

Many biliary strictures encountered during endoscopic retrograde cholangiopancreatography (ERCP) of jaundiced patients are malignant. However, histological confirmation of malignancy is often not achieved. Rational decisions about treatment depend on a definite diagnosis and the quality of information provided to the patient regarding prognosis is severely compromised by doubt over diagnosis. ${ }^{1}$

Non-invasive radiological techniques, including ultrasound, computed tomography (CT), and magnetic resonance imaging, are able to provide useful information about the extent of biliary dilatation and the presence or absence of a mass in the head of the pancreas, and are able to identify metastatic disease. These techniques have the limitation that they are unable to provide a definite histological diagnosis, unless they are used to guide percutaneous biopsy or percutaneous fine needle aspiration. Percutaneous sampling techniques are invasive and carry risks of disseminating early tumour. ${ }^{23}$

Several techniques have been described to obtain tissue for cytological or histological diagnosis at the time of ERCP. They include intraductal collection of bile for cytology, ${ }^{4}$ and various endoluminal collection methods: brush cytology, endoscopic forceps biopsy, scrape biopsy, and cytology from a retrieved stent. ${ }^{5-8}$ Several groups have published retrospective reviews of their experience with one or two of these methods, ${ }^{9-11}$ but there are few prospective comparative studies, ${ }^{12}$ and in no previous study have all these techniques been directly prospectively compared. ${ }^{1}$

The aim of this study therefore was to compare these ERCP techniques for tissue sampling in jaundiced patients with potentially malignant biliary strictures. The question of whether one sampling technique was sufficient or whether a combination of samples represented optimal clinical practice was considered. In addition, two methods of presenting the cytology specimens, slides made at endoscopy or cytology washings, were compared. ${ }^{13}$

\section{Methods}

PATIENTS

Over a 15 month period (March 1994 to June 1995) all patients with biliary strictures suspicious of malignancy undergoing ERCP at this unit were entered into the study. This resulted in 54 ERCP procedures providing samples for analysis, on a total of 43 patients. Four patients underwent two procedures each, two patients three procedures, and one patient four. All the repeat procedures were performed to replace obstructed biliary stents. 
The 54 ERCPs were performed on 24 men and 30 women, median age 69 , range 37 to 92 . The median duration of their current illness was three months, with a range of two weeks to two and a half years. Their mean bilirubin concentration was 189 (range 5-610, normal <20) mmol, the mean alkaline phosphatase concentration was 599 (range 82-2027, normal 40-120) IU/l, and alanine aminotransferase was 142 (range 17-646, normal <45) IU/.

ERCP AND SAMPLE COLLECTION

The ERCPs were carried out using side viewing duodenoscopes (Olympus TJF 10 or JF1T200). Patients received intravenous broad spectrum antibiotics before the procedure and supplemental nasal oxygen before and during the period of intravenous sedation. Pulse oximetry and blood pressure monitoring were performed on all patients. Sedation was with intravenous pethidine, or benzodiazepine (midazolam or diazemuls), or both. Informed consent was obtained.

After visualisation of the biliary stricture a flexible tipped guide wire (Zebra wire, Microvasive, Boston Scientific) was negotiated through. Brush cytology samples were then taken by passing a wire guided sheathed cytology brush (Combocath, Microvasive, Boston Scientific). This single use brush has a double lumen construction, one lumen for the guide wire - which remains in place across the stricture throughout - and the other contains the sheathed brush which is advanced up the stricture only when the sheath is at the lower end of the stricture (Fig 1). The brush was advanced up and down the stricture five times before being resheathed and the sheathed brush was then withdrawn from the endoscope (Fig 2).

The cytology specimen was immediately transferred to glass slides by smearing the cellular material from the brush directly on to two slides. The slides were coded and immersed in fixative. The brush was then

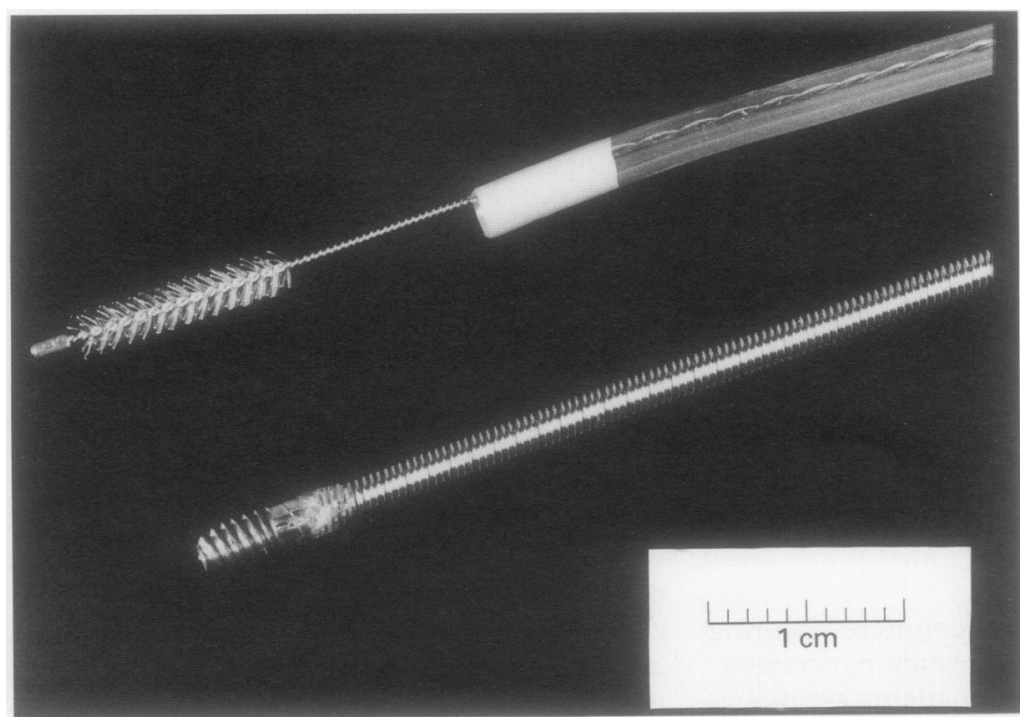

Figure 1: Cytology brush and Soehendra stent retriever.

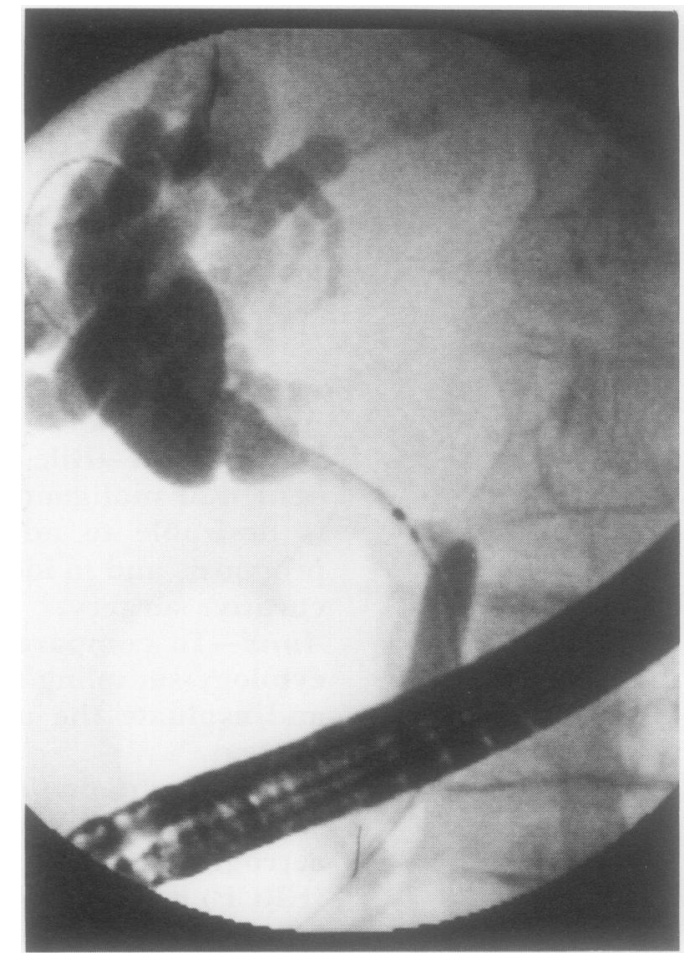

Figure 2: Fluoroscopic appearance of cytology brush in a biliary stricture.

washed vigorously in fixative to dislodge any further sample. These washings were then coded and despatched to the cytologist.

With the guide wire remaining across the stricture after withdrawal of the brush an $11.5 \mathrm{~F}$ Soehendra stent retriever (Wilson Cooke) was advanced over the wire until it abutted the lower end of the stricture. The tip of the stent retriever has a "self tapping" external thread designed to thread the interior of plastic stents before stent removal (Fig 1). When positioned below the stricture clockwise rotation of the torque transmitting Soehendra instrument pulled the tip into and across the stricture as previously described ${ }^{8}$ Progress of the stent retriever through the stricture was checked using fluoroscopic screening. When it reached the top of the stricture it was pulled back into the endoscope and withdrawn. Samples were then prepared from the tissue retained in the screw thread in a similar way to the brush samples above - that is, by smearing on to two cytology slides and washing in fixative.

After removal of the Soehendra stent retriever the guide wire again remained in place and a plastic biliary drainage stent was then inserted over an introducing catheter passed over the guide wire in the usual way. Once a satisfactory position had been achieved and the guide wire was withdrawn a $20 \mathrm{ml}$ sample of bile was aspirated from directly above the stricture via the introducing catheter. The bile sample was sent for exfoliative biliary cytology and the introducing catheter and endoscope were removed as usual.

In 19 cases the ERCP was performed to replace a blocked biliary stent. In these cases the ERCP began with endoscopic removal of the stent from the bile duct using a wire snare. 
On removal the tissue - including sludge and sometimes blood clot around the proximal flap of the retrieved stent - was first smeared on to two glass slides and then washed in cytology fixative.

In patients in whom a sphincterotomy was required to allow passage of the stent, biopsies of the stricture were also performed with biopsy forceps passed up the bile duct through the sphincterotomy. Sphincterotomies were not performed routinely because they are known to increase significantly the risk of serious bleeding complications and unnecessarily prolong the procedure. ${ }^{14}$ At the outset of the study it was anticipated that sphincterot- omies would be needed more often. In fact, biopsy specimens were taken on only four occasions by this method.

PROCESSING OF SAMPLES

All samples were coded at the time of ERCP and sent to an expert specialist cytologist (VW), who was blinded to the clinical details and methods of sampling. Samples were scored for adequacy ( 0 =unsatisfactory, $1=$ scanty, $2=$ adequate) and for malignancy ( $1=$ unsatisfactory, $2=$ no malignant cells seen, $3=$ atypical cells ?reactive, $4=$ suspicious of malignancy, and $5=$ clearly malignant) (Fig 3 ).
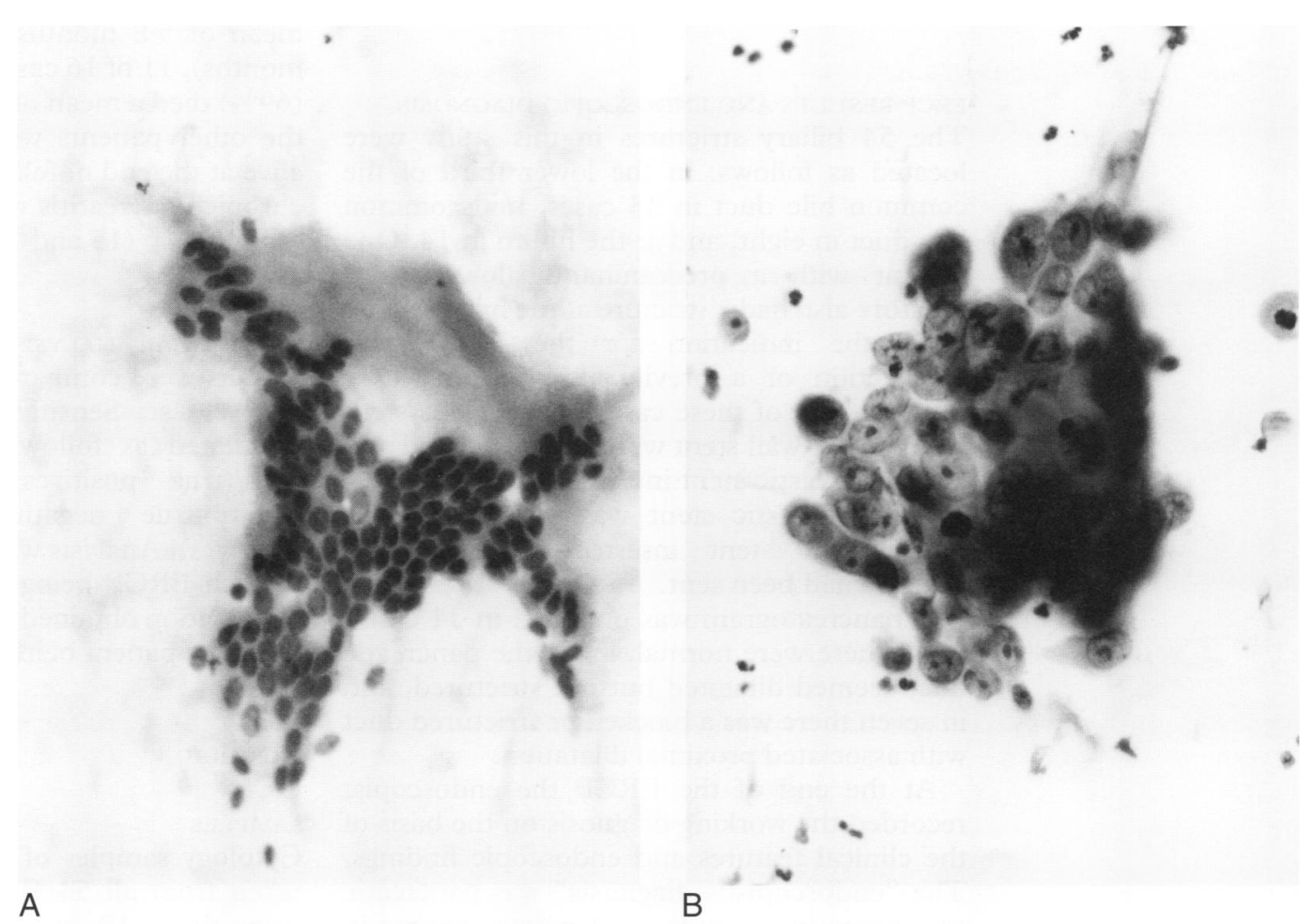

A

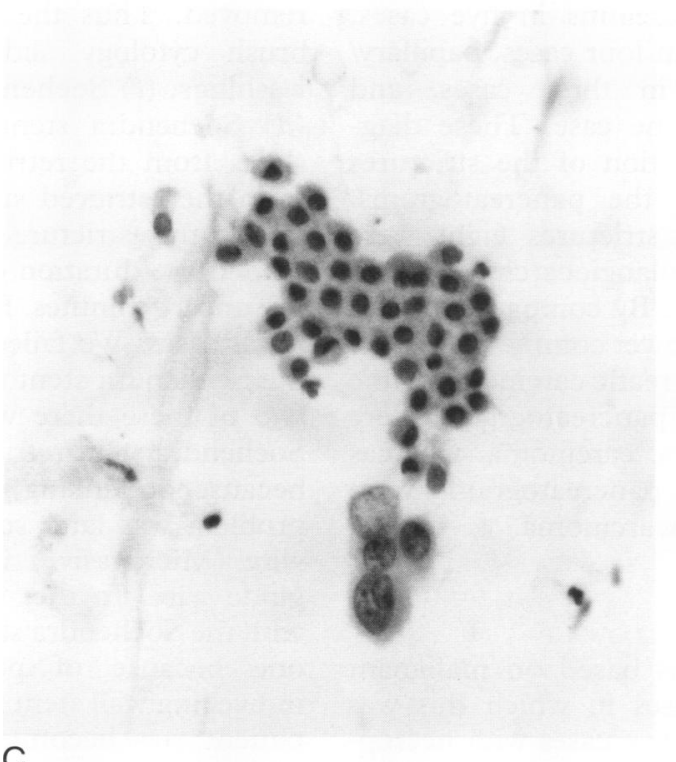

Figure 3: Examples of cytology slides. (A) Brush specimen showing a sheet of normal biliary epithelium (Papanicolaou stain, originally $\times 400$ ). (B) Brush cytology showing a group of malignant cells from a positive specimen (Papanicolaou stain, originally $\times 400)$. (C) Brush cytology showing a small group of atypical cells suspicious of malignancy, adjacent to a sheet of benign epithelium. The specimen was scanty (Papanicolaou stain, originally $\times 400$ ). 
METHOD OF FOLLOW UP

Details of the patients were recorded at the time of ERCP on a form designed for the study. The cytology results were collated on this form as was the clinical follow up information.

Patients were followed up for a minimum of seven months, maximum 18 months. The case records were reviewed to obtain details of all other diagnostic tests, including radiology and subsequent ERCPs, if any. Clinical progress and, where appropriate, date and cause of death were recorded. If a necropsy had been performed the result was documented. When necessary the patient's general practitioner was contacted to complete follow up information, and the family health service authority (FHSA) to provide date of death.

ERCP RESULTS AND ENDOSCOPIC DIAGNOSIS The 54 biliary strictures in this study were located as follows: in the lower third of the common bile duct in 33 cases, mid-common bile duct in eight, and at the hilum in 14. One patient with a predominantly lower third stricture also had a stricture at the hilum. In 20 cases the indication for the ERCP was obstruction of a previously inserted biliary stent. In one of these cases the previous stent was a metal wall stent which was dilatated and a further plastic stent inserted. In the other 19 cases the plastic stent was removed and a replacement stent inserted after cytology samples had been sent.

A pancreatogram was obtained in 34 cases; 20 of these were normal, in six the pancreatic duct seemed dilatated but not strictured, and in seven there was a blocked or strictured duct with associated proximal dilatation.

At the end of the ERCP the endoscopist recorded the working diagnosis on the basis of the clinical features and endoscopic findings. The "endoscopist's diagnosis" was pancreatic carcinoma in 25 cases, cholangiocarcinoma in 15 cases, chronic pancreatitis in five cases, metastatic malignancy in four cases, papillary/ ampullary carcinoma in three cases, and diagnosis deferred in one case. These diagnoses reflected the location of the strictures and information from the pancreatograms. Thus of the 14 hilar strictures eight were thought to represent cholangiocarcinomas and three metastatic disease. By comparison 21 of the 33 strictures of the lower common bile duct were thought to be pancreatic carcinoma. Nine of the 13 abnormal pancreatograms were interpreted as pancreatic carcinoma, whereas 11 of the 20 normal pancreatograms were interpreted as cholangiocarcinoma.

FINAL DIAGNOSIS AND FOLLOW UP

The final diagnosis was based on malignant histology in the 18 cases in which this was available; this included five cases with necropsies. In 24 cases clinical deteroration to death and radiology consistent with malignancy were the basis of the diagnosis. In a further 10 the clinical progression of the disease and the radiology indicated a malignant diagnosis. In two cases the clinical features, radiology, and survival indicated chronic pancreatitis as the benign cause of the biliary stricture.

Carcinoma of the pancreas was the final diagnosis in 28 cases, cholangiocarcinoma in 16 , ampullary carcinoma in three, metasatic malignancy in five (two carcinomas of the bowel, one adenocarcinoma with widespread metasases but unknown primary, one carcinoma of breast, and one malignant melanoma). Two cases were chronic pancreatitis.

The survival after ERCP was dependent on the diagnosis and frailty of the patient. Of the 37 patients who died during follow up the mean survival was five months, range one week to 18 months. Twenty one of 28 cases of carcinoma of the pancreas $(75 \%)$ died after a mean of 5.8 months (range one week to 18 months), 11 of 16 cases of cholangiocarcinoma $(69 \%)$ died a mean of 3.6 months after ERCP; the other patients with these diagnoses were alive at the end of follow up. The patients with chronic pancreatitis were both alive at the end of follow up (15 and 19 months).

\section{STATISTICAL ANALYSIS}

Results were compared between groups using the $\chi^{2}$ test. Sensitivity and specificity were calculated as follows: Sensitivity=true positives/(true positives+false negatives); specificity $=$ true negatives(true negatives + false positives). Analysis was performed on the basis of each ERCP being a separate investigation, information obtained from previous ERCPs on the same patient being disregarded.

\section{Results}

\section{SAMPLES}

Cytology samples of five different types were taken from all 54 ERCPs and a further two from those 19 in which a bilary stent was removed. Thus the whole set included: (a) brush cytology slides, (b) brush cytology washings, $(c)$ Soehendra stent retriever slides, (d) Soehendra stent retriever washings, (e) slides from the retrieved stent, $(f)$ washings from the retrieved stent, $(g) 20 \mathrm{ml}$ bile from above the stricture. Sample collection extended the duration of the ERCP by between five and 10 minutes. Brushings were performed in all cases. We failed to obtain samples with the Soehendra stent retriever in four cases. In two of these there was difficulty passing the Soehendra stent retriever up into the bile duct because of kinking of the guide wire. This problem was later solved by using the Zebra wire (Microvasive) in place of the standard guide wire. In the other two cases sampling with the Soehendra stent retriever was avoided, one because of potential damage to an indwelling wall stent and the other because the patient was becoming restless and therefore maintaining a satisfactory scope position was difficult.

The quality of each sample was reported by the cytologist (VW) as unsatisfactory, scanty, 
TABLE I Quality of cytology samples $\mathrm{v}$ method of sampling

\begin{tabular}{lccc}
\hline & $\begin{array}{l}\text { Unsatisfactory } \\
\text { or no sample }\end{array}$ & Scanty & $\begin{array}{l}\text { Adequate } \\
n(\%)\end{array}$ \\
\hline Brush cytology slides (n=54) & 1 & 6 & $47(87)$ \\
Brush cytology washings (n=54) & 3 & 2 & $49(91)$ \\
Soehendra SR slides (n=50) & 7 & 13 & $30(60)$ \\
Soehendra SR washings (n=50) & 6 & 10 & $34(68)$ \\
Retrieved stent slides (n=19) & 2 & 1 & $14(74)$ \\
Retrieved stent washings (n=19) & 2 & 10 & $23(44)$ \\
Bile (n=52) & 19 & 22 & $91(74)$ \\
All slides (n=123) & 10 & 13 & $99(80)$ \\
All washings (n=123) & 11 & &
\end{tabular}

or adequate (Table I). Both brush samples and samples from retrieved blocked stents provided a high proportion of adequate samples ( $96 \%$ and $84 \%$ respectively). The quality of the brush samples was generally more reliable than the Soehendra stent retriever samples $(96 \%$ adequate $v 70 \%, \chi^{2}=13, \mathrm{p}<0.001$ ), but in two cases the brush samples were unsatisfactory whereas the Soehendra stent retriever provided adequate specimens. The bile samples were clearly very inferior, only $44 \%$ were classed as adequate and in $36 \%$ there were no cells for cytological analysis.

Comparison between cytology slides and washings showed them to be equally effective. In 123 samples both slides and washings were sent; $74 \%$ were adequate on the slides, $80 \%$ on the washings $\left(\chi^{2}=1 \cdot 5, N S\right)$ and using both methods adequate samples were obtained in $86 \%$.

\section{DETECTION OF MALIGNANCY}

The cytological detection of malignancy was defined as cases in which the cytologist reported clearly malignant cells or cells suspicious of malignancy, and in which the final diagnosis was of malignant biliary stricture (true positives). Malignancy was detected by brush cytology in 22 cases $(42 \%$ of all cases with a final diagnosis of malignancy). The Soehendra stent retriever added a further three cases but would only have detected 13 cases if used as the only sampling method. Cytology from the retrieved stents would alone have detected seven cases, compared with six cases of positive brush cytology in these 19 cases with retrieved stents. Exfoliative bile cytology detected six cases of malignancy, all but one of which were also detected by brush cytology. Using a combination of all the cytology sampling modalities in this study 14 cases were identified as clearly malignant and 14 as suspicious of malignancy. Overall, the combined cytology methods disclosed a sensitivity of $54 \%$. This reflects the 24 cases of negative cytology

TABLE II Malignant cytology results $\mathrm{v}$ final diagnosis

\begin{tabular}{lllllll}
\hline & Brush & $\begin{array}{l}\text { Soehendra } \\
\text { SR }\end{array}$ & $\begin{array}{l}\text { Retrieved } \\
\text { stent }\end{array}$ & Bile & $\begin{array}{l}\text { All detected } \\
\text { malignancies }\end{array}$ & $\begin{array}{l}\text { Cytology } \\
\text { negative }\end{array}$ \\
\hline All malignancies $(\mathrm{n}=52)$ & 22 & 13 & 7 & 6 & 28 & 24 \\
Pancreatic carcinoma $(\mathrm{n}=28)$ & 10 & 7 & 4 & 0 & 14 & 14 \\
Cholangiocarcinoma $(\mathrm{n}=16)$ & 10 & 6 & 3 & 4 & 12 & 4 \\
Metastatic carcinoma (n=5) & 2 & 2 & 0 & 2 & 2 & 3 \\
Ampullary carcinoma ( $\mathrm{n}=3)$ & 0 & 0 & 0 & 0 & 0 & 3 \\
Chronic pancreatitis $(\mathrm{n}=2)$ & 0 & 0 & 0 & 0 & 0 & 2 \\
\hline
\end{tabular}

with a final diagnosis of malignancy (false negatives).

When the different final diagnoses were analysed separately the sensitivity for cholangiocarcinoma was $75 \%$, pancreatic carcinoma $50 \%$, and metastatic carcinoma $40 \%$. These calculations are based on cytology reports of clearly malignant and suspicious of malignancy being indicative of malignancy. If only reports of clearly malignant were included the sensitivity was lower: cholangiocarcinoma $44 \%$, pancreatic carcinoma $18 \%$. All the sampling methods were similar in being more effective at identifying tumours arising from the bile duct than from pancreas (Table II)

Biopsy of the bile duct stricture was only performed in four cases. Two of these were ampullary tumours and one was a cholangiocarcinoma and one a pancreatic neoplasm. The biopsy specimens provided histologically malignant tissue in one of the ampullary tumours and in the cholangiocarcimoma, but no malignant tissue was seen in the other two cases. In the case of the ampullary tumour the positive biopsy specimen was the only sample to yield a malignant diagnosis as the cytology specimens were atypical with ?reactive changes.

Two cases had a final diagnosis of benign chronic pancreatitis. Both patients are still alive and well. The cytology samples from these patients were all benign, but clearly this is too few patients with benign disease to confirm meaningfully the sensitivity of $100 \%$.

In 11 cases the cytology was reported as "atypical cells, ?reactive changes". This referred to definitely abnormal cells but without cytological features of malignancy. In three of these cases malignancy was identified in one or more of the other samples, but in the remaining eight the other samples were benign. All these cases with atypical cells had a final diagnosis of malignancy: pancreatic carcinoma in nine, cholangiocarcinoma in one, and ampullary carcinoma in one. If these atypical cytology reports were to be interpreted as positive the overall sensitivity would rise to $69 \%$ and the sensitivity for pancreatic carcinoma to $79 \%$.

In the 11 ERCPs which were performed on patients who had already undergone one ERCP earlier in the study the diagnosis of malignancy on brush cytology was made in five of the 11 cases $(45 \%)$. This compared with 17 of $41(41.5 \%)$ of the malignancies detected by brushing in the non-repeated cases (NS). Neither previous cytology sampling nor previous biliary stenting made any difference to the likelihood of positive cytology.

When the endoscopist's diagnosis at the end of the ERCP was compared with the final diagnosis there were six occasions when the initial diagnosis proved incorrect, five cases turning out to be malignant when benign disease seemed likely and one case of chronic pancreatitis in which malignancy was diagnosed by the endoscopist. In all these cases the cytological diagnosis proved correct. 


\section{Discussion}

This is the first prospective study to compare four different methods of cytology sampling from biliary strictures. It has clearly identified brush cytology as the best technique of the four under study. Exfoliative bile cytology performed poorly compared with cytology brush sampling. It had been hoped that the Soehendra stent retriever might provide an even better sampling method than brushings, as the screw thread of the stent retriever engages in the tissue of the stricture and potentially allows for cells deeper in the bile duct mucosa to be sampled. ${ }^{8}$ This study has shown that this is not the case, the cytology brush samples were more likely to be of adequate cellularity and more likely to identify malignancy than those from the stent retriever.

Previous reports of the value of brush cytology in biliary strictures have provided a wide range of sensitivity: zero to $91 \%$ for pancreatic carcinoma and $20 \%$ to $100 \%$ for cholangiocarcinoma (Table III). ${ }^{6-12}{ }^{15-18}$ This wide variation, mainly based on small studies, highlights the need for relatively large prospective comparative studies such as this to provide an assessment of the real value. Several previous studies have taken the form of retrospective reviews of two or more different methods, this approach has been compromised because patients in whom there was doubt over the final diagnosis were often excluded on the grounds of insufficient follow up. ${ }^{9} 10161920$ Other studies have been reported by the originators of particular methods whose results and technical expertise may not always be reproducible by other teams. ${ }^{812}$ Patient selection also varies between studies, in our series all potentially malignant biliary strictures coming through our unit were included and the ERCP was generally performed early in the course of investigations, often before CT, percutaneous biopsy, or exploratory laparotomy. In other studies patients have been more intensively investigated before ERCP and cytology performed on a more selected group of patients. Our results of $38 \%$ of pancreatic carcinoma and $63 \%$ of cholangiocarcinoma detected by brush cytology show what can be expected from routine use of this technique in all biliary strictures.

The design of the cytology brush used in this study seems efficient in that the brush is sheathed to avoid loss of sample in the endoscope $^{21}$ and because it is wire guided it can be

TABLE III Detection of malignancy by brush cytology

\begin{tabular}{|c|c|c|c|}
\hline Reference & Year & $\begin{array}{l}\text { Pancreatic } \\
\text { carcinoma } \\
(\%)\end{array}$ & $\begin{array}{l}\text { Cholangio- } \\
\text { carcinoma } \\
\text { (\%) }\end{array}$ \\
\hline 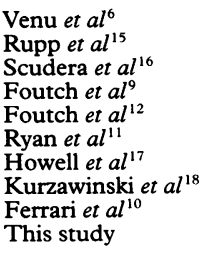 & $\begin{array}{l}1990 \\
1990 \\
1990 \\
1990 \\
1991 \\
1991 \\
1992 \\
1993 \\
1994 \\
1996\end{array}$ & $\begin{array}{r}3(60) \\
21(91) \\
5(50) \\
5(50) \\
0(0) \\
6(30) \\
0(00) \\
15(65) \\
16(66) \\
10(38)\end{array}$ & $\begin{array}{l}20(80) \\
6(100) \\
2(100) \\
2(100) \\
5(100) \\
4(44) \\
2(40) \\
6(60) \\
2(20) \\
10(63)\end{array}$ \\
\hline Total & & $80(48)$ & $63(67)$ \\
\hline
\end{tabular}

used without difficulty once deep cannulation of the common bile duct has been achieved.

This study has shown that there is an additional benefit to using multiple sampling methods, increasing the sensitivity from $38 \%$ to $50 \%$ for carcinoma of the pancreas and from $63 \%$ to $75 \%$ for cholangiocarcinoma. Whether this is worthwhile will ultimately depend on the value attached to each additional diagnosis confirmed. It would seem prudent to use both brushings and retrieved stents for cytology samples whenever possible. The addition of Soehendra stent retriever and exfoliative biliary cytology to the other methods in our series added only another three malignancies.

We prefer to avoid performing a sphincterotomy in jaundiced patients wherever possible to minimise complications. ${ }^{14}$ For this reason only four patients had biopsy specimens taken from their biliary strictures. Of these one provided confirmation of an ampullary tumour but the other three did not add to the information provided by the cytology samples. The recently developed bile duct biopsy forceps may enable biliary strictures to be biopsied more easily. Sensitivities of $64 \%-81 \%$ have been reported with such biopsy specimens although many patients did require a sphincterotomy before biopsy. ${ }^{22} 23$

Cytology slides and cytology washings have not been compared before in this setting although both are in common use. ${ }^{24}$ In this study we have shown that either technique gave satisfactory samples in $74 \%-80 \%$ of cases and scanty samples in $11 \%-18 \%$, and using both slides and washings increased this to $86 \%$ adequate, $11 \%$ scanty, and only $3 \%$ unsatisfactory.

The difference in sensitivity between cholangiocarcinoma $(75 \%)$, and pancreatic carcinoma $(50 \%)$ reflects the closer proximity of the biliary stricture to the primary pathology when the tumour is of bile duct origin. Other groups have also reported this trend. ${ }^{9} 1013$ Endoscopic fine needle aspiration using a specially designed needle may allow improvement in the sampling of pancreatic tumours causing bile duct strictures. One report using this approach enabled $73 \%$ of pancreatic carcinomas to be correctly identified ${ }^{17}$ but further prospective comparative assessment of this method is needed.

In this study eight cases with a final diagnosis of pancreatic carcinoma had abnormal cells but lacked specific features of malignancy on cytology. These were reported as "atypical ?reactive" and similar findings have been a feature of other biliary cytology series. ${ }^{13}{ }^{19}$ In our study the numbers of patients with benign disease was small and we cannot be sure that atypical/reactive appearances are specific to malignancy. Layfield et $a l^{19}$ reviewed 180 patients with biliary cytology samples, of whom 108 had sufficient follow up to be included. They reported nine patients with reactive cytology and six with low grade dysplasia. One of the reactive group and three of the low grade dysplasia group had a final diagnosis of malignancy. In view of this, reactive changes should continue to be regarded with caution 
rather than included in the malignant category as some investigators have suggested. ${ }^{13}$ Flow cytometry for DNA analysis of brush cytology samples from biliary strictures has been used in an attempt to improve the results in cases of atypical cells, but was associated with an increased false positive rate. ${ }^{25}$

The challenge for future developments in this field is to develop better methods of sampling deeper to the biliary mucosa so as to detect malignant cells causing biliary stricture by compression and invasion. New developments with fine needle aspiration techniques and new equipment small and flexible enough to introduce into the bile duct are exciting, although to be easily used in routine practice they will require a method of wire guided insertion to allow access to difficult strictures. Endoscopic ultrasound also has the potential to assist with accurate sampling, especially if combined with fine needle aspiration sampling. Future technical advances will need to be tested in further prospective comparative studies before their true value can be assessed.

In conclusion, this study has disclosed the limitations of biliary cytology. Careful sampling of potentially malignant biliary strictures by up to five different methods enabled $75 \%$ of cholangiocarcinomas and $50 \%$ of pancreatic carcinomas to be confirmed. Brush cytology was the best sampling method, although samples from retrieved stents provided additional worthwhile information. These techniques are simple to use and should be routine clinical practice whenever potentially malignant strictures are encountered at ERCP.

We thank the nursing staff on the endoscopy unit at the Royal Victoria Infirmary for their help with this study. We are gratefu for help from Dr Hemming, Pathology Department, Hexham General Hospital, in the preparation of Fig 3. No financia assistance was obtained. Some of the results of this study have been published in abstract form (Gut 1995; 37 (suppl 2): A2).

1 Kurzawinski T, Deery A, Davidson BR. Diagnostic value of cytology for biliary stricture. Br F Surg 1993; 80: 414-21.

2 Ferrucci JT, Wittenberg J, Margolies MN, Carey RW Malignant seeding of the tract after thin-needle aspiration biopsy. Radiology 1979; 130: 345-6.

3 Warshaw AL. Implication of peritoneal cytology for staging of early pancreatic surgery. Am ₹ Surg 1991;161: 26-9.

4 Davidson B, Varsamidakis N, Dooley J, Deery A, Dick R, Kurzawinski T, Hobbs K. Value of exfoliative cytology for investigating bile duct strictures. Gut 1992; 33: 1408-11.
5 Foutch PG, Harlan JR, Kerr D, Sanowski RA. Wire-guided brush cytology: a new endoscopic method for diagnosis of bile duct cancer. Gastrointest Endosc 1989; 35: 243-7.

6 Venu RP, Geenen JE, Kini M, Hogan WJ, Payne M, Johnson K, Schmalz MJ. Endoscopic retrograde brush cytology: a new technique. Gastroenterology 1990; 99: cytology:

7 Leung JWC, Sung JY, Chung SCS, Chan KM. Endoscopic scraping biopsy of malignant biliary strictures. Gastrointest Endosc 1989; 35: 65-6.

8 van Someren RNM, Benson MJ, Ainley CC, Glynn MJ, Swain CP. A novel endoscopic method for dilating difficult biliary strictures. Gastrointest Endosc 1996; 43: 495-8.

9 Foutch PG, Kerr D, Harlan JR, Manne JR, Kummet TD, Sanowski RA. Endoscopic retrograde wire-guided brush cytology for diagnosis of patients with malignant obstruction of the bile duct. Am $\mathcal{F}$ Gastroenterol 1990; 85: 791-5.

10 Ferrari AP, Lichtenstein DR, Slivka A, Chang C, CarrLocke DL. Brush cytology during ERCP for the diagnosis of biliary and pancreatic malignancies. Gastrointest Endosc of biliary and pan

11 Ryan ME. Cytologic brushings of ductal lesions during ERCP. Gastrointest Endosc 1991; 37: 139-42.

12 Foutch PG, Kerr D, Harlan JR, Kummet TD. A prospective, controlled analysis of endoscopic cytotechniques for diagnosis of malignant biliary strictures. $\mathrm{Am} f$ Gastroenterol 1991; 86: 577-80.

13 Wiersema M, Lehman G, Hawes R, Sherman S, Earle D. Improvement of diagnostic yield of brush cytology in malignant biliary strictures by the use of supplemental tissue sampling techniques [abstract]. Gastrointest Endosc 1992; 38: 265 .

14 Cotton PB. Endoscopic management of bile duct stones. (Apples and oranges.) Gut 1984; 25: 587-97.

15 Rupp M, Hawthorne CM, Ehya H. Brushing cytology in biliary tract obstruction. Acta Cytol 1990; 34: 221-6.

16 Scudera PL, Koizumi J, Jacobson IM. Brush cytology evaluation of lesions encountered during ERCP. Gastrointest Endosc 1990; 36: 281-4.

17 Howell DA, Beveridge RP, Bosco J, Jones M. Endoscopic needle aspiration biopsy at ERCP in the diagnosis of biliary strictures. Gastrointest Endosc 1992; 38: 531-5.

18 Kurzawinski TR, Deery A, Dooley JS, Dick R, Hobbs KEF, Davidson BR. A prospective study of biliary cytology in 100 patients with bile duct strictures. Hepatology 1993; 18: $1399-403$.

19 Layfield LJ, Wax TD, Lee JG, Cotton PB. Accuracy and morphologic aspects of pancreatic and biliary duct morphologic aspects of pancreatic

20 Rabinovitz M, Zajko AB, Hassanein T, Shetty B, Bron KM, Schade RR, et al. Diagnostic value of brush cytology in the diagnosis of bile duct carcinoma: a study in 65 patients with bile duct strictures. Hepatology 1990; 12: 747-52.

21 Baron TH, Lee JG, Wax TD, Schmitt CM, Cotton PB Leung JWC. An in vitro, randomized, prospective study to maximize cellular yield during bile duct brush cytology. Gastrointest Endosc 1994; 40: 146-9.

22 Chang L, French S, Hierro M, Lo SK. A prospective study comparing endobiliary biopsy, brush and aspiration cytology during ERCP in diagnosing biliary obstructive lesions [abstract]. Am $\mathcal{F}$ Gastroenterol 1992; 87: 1282 .

23 Kubota Y, Takaoka M, Tani K, Ogura M, Kin $\mathrm{H}$ Fijimura $\mathrm{K}$, et al. Endoscopic transpapillary biopsy for diagnosis of patients with pancreaticobiliary ductal diagnosis of patients with pancreaticobiliary
strictures. Am $\mathcal{F}$ Gastroenterol 1993; 88: 1700-4.

24 Wiersema MJ, Lehman GA. ERCP biopsy and cytology techniques. In: Barkin JS, O'Phelan CA, eds. Advanced therapeutic endoscopy. 2nd edn. New York: Raven Press, 1994: 291-8.

25 Ryan ME, Baldauf MC. Comparison of flow cytometry for DNA content and brush cytology for detection of malignancy in pancreaticobiliary strictures. Gastrointest Endosc 1994; 40: 139-9. 